\title{
Making mediated memory work: Cuban-Americans, Miami media and the doings of diaspora memories
}

Media, Culture \& Society 20l4, Vol. 36(6) 776-789

(C) The Author(s) 2014 Reprints and permissions: sagepub.co.uk/journalsPermissions.nav DOI: I0.1I77/01634437|3518574 mcs.sagepub.com

(S)AGE

\section{Christine Lohmeier}

University of Munich, Germany

\section{Christian Pentzold}

Technische Universität Chemnitz, Germany

Alexander von Humboldt Institute for Internet and Society, Berlin, Germany

\begin{abstract}
How are mediated memories brought into being? In other words, how can we understand the ways personal and public memories are enacted in environments that have become increasingly digitally networked? Following this fundamental question for current interrogations of the entanglement of media and memory, we first develop a concept of mediated memory work. Instituting experiences and senses of the past, these time- and space-bound efforts interweave with arrangements of people and their social relations, cultural discourses, objects and media environments. Capitalizing on such an understanding of mediated memory work, the article demonstrates how and to what ends the enactment of memories can be empirically studied by using the example of the Cuban-American community in Miami. In particular, building on participant observation, in-depth interviews and media ethnography, we outline practices, cultural artefacts, communal bonds, compassionate relations and a media manifold that have been employed by different segments of a diasporic collective in shaping how the country of origin and the exile is to be remembered.
\end{abstract}

\section{Keywords}

Cuban-Americans, diaspora, exile, media memory, media practices, mediation, mediatization, memory, memory work

\section{Corresponding author:}

Christine Lohmeier, University of Munich, Department of Communication Science and Media Research, Oettingenstr. 67, 80538 Munich, Germany.

Email: christine.lohmeier@yahoo.co.uk 


\section{Mediating memories}

When all walks of life seem to be mediated, people handle ever more ways to note, share and keep their expressions and impressions, as well as to access vast archives of such records. Almost ubiquitous communication services and mobile devices are employed to track and store our activities, interactions, feelings and relations, permanently and continuously, it seems (Mayer-Schönberger, 2009). For sure, since the very beginnings of human culture, personal and collective memories have been constituted and passed down through memorable objects and symbolic representations that form part of acts of commemoration (see e.g. Erll and Rigney, 2009; Olick et al., 2011; Rossington and Whitehead, 2007). In the wake of the general academic current driving the study of such mediated memories, scholarly attention has centred on mainstream media like television, books, films, newspapers, magazines and radio, and was until recently mainly occupied with emblematic texts and images of traumatic, festive and other noteworthy events. Thus, media were seen as mnemonic repositories and agents that garner, assemble, canonize and disseminate messages so as to form commemorative publics (e.g. Assmann, 2011; Edy, 2006; Garde-Hansen, 2011; Neiger et al., 2011; Zandberg, 2010; Zelizer, 2000).

From manuscript and print via broadcast media to the rise of networked electronic infrastructures and digital media, socio-technological innovations have always helped to reassemble the practices and materials people use to form personal memories and hand down artefacts, techniques and discourses from which shared memories are constructed. Consequently, given the swift appearance, broad diffusion and the often-asserted profound impact of novel connective and mobile devices, services and applications, we find a growing body of literature studying new forms, technologies and dynamics of evolving digitally mediated memories (e.g. Foot et al., 2005; Garde-Hansen et al., 2009; Haskins, 2007; Hess, 2007; Pentzold, 2009; Reading, 2003).

In general, this strand of scholarship explores the multitude of mediated memories that evolve in intricate relations with hegemonic views of the past and the registers of common cultural memories. It thus examines how social media constitute a plethora of vernacular memories that conflict and ally, contest and reverberate in many different dynamics, transcending and re-establishing temporal, local, technological and social boundaries. In this regard, references to the 'mediation of everything' (Livingstone, 2009:1) highlight the proliferation of media and the complex interweaving of social lives, and thus of personal and collective memories, with various sorts of media and types of communication. The notion of mediated memories consequently goes beyond the insight that the representation of the past is embedded in the forms and the regimes of evolving media. Hence, Hoskins (2009: 28) maintains that the mediation of memories does not merely come as an unintended consequence of pervasive media. Instead, it involves, he argues, reflexive and self-conscious practices of articulating and devising senses of the past in environments of extensive connectivity with 'supersaturated' (Couldry, 2012: 5) flows of visuals, texts and other types of messages.

Acknowledging the complexities of the multi-level transformations named 'mediation' and following the demand to approach such mediation of memory through the 'mangle of practice' (Pickering, 1995), this article seeks to substantiate the proposition 
that such mediated memories are actively and purposefully instantiated. It does so conceptually and empirically. ${ }^{1}$ Its focus shifts from registering a battery of possible technological and social factors of mediation to examining how mediated memories are being enacted by agents using technological means as well as cultural artefacts and discourses. Overall, the goal is to provide an understanding of mediated memory work based in theories of social practices and stemming from empirical research on the interweaving of individual remembering, collective memories and a socio-material world suffused by media.

This article aims to contribute to memory studies, and particularly to scholarship on mediated memories, in two ways: it conceptualizes mediated memory work as bundles of bodily and materially grounded practices to accomplish memories in and through media environments. It then demonstrates how such an understanding translates into empirical research by examining practices and arrangements of memories enacted within the Cuban-American community in Miami. Consequently, issues of diasporic memories as well as the material, spatial and mobile aspects of remembrance are addressed.

In what follows, we first draw on debates on the performance and the mediation of memories to develop the notion of mediated memory work. Second, building on participant observation, qualitative in-depth interviews and media ethnography, we investigate how characteristic sorts of memory work, cultural artefacts, media environments, experiences and social relations have been employed by different Miami-based groups of Cuban-Americans to configure what is remembered of home and of the exodus.

\section{Performing memory}

There are several starting points for an interrogation of the performance of memory on a personal and a social level in theories of memory (Garde-Hansen, 2011: 20-49). For instance, Bergson (1988 [1896]: 80-9) distinguished between 'habit memory' and 'representational memory'. Explaining this, he takes memory to be, on the one hand, the corporeal and habitual dispositions gained through mimicry and repeated acts of memorialization. On the other, he views memory as acts of imagination that evoke and bring to mind past events and experiences. In the same vein, Connerton (1989: 102) explains two modes through which cultural memory operates: first, through a 'cognitive mode' as people retrieve events and experiences from the past through present acts of remembering. Second, a sense of the past is brought about through the 'performative mode' of commemorative acts.

To take these insights further, we posit that the concept of memory work could be of some use here. For van Dijck (2007: 5), memory work 'involves a complex set of recursive activities that shape our inner worlds, reconciling past and present, allowing us to make sense of the world around us, and constructing an idea of continuity between self and others'. Furthermore, Kuhn (2010: 303) suggests that 'memory work is an active practice of remembering that takes an inquiring attitude towards the past and the activity of its (re)construction through memory'. This and other definitions of memory work emphasize the conscious and purposive staging of memory, often in terms of therapy, reconciliation and sense-making (see Haug, 1992; Onyx and Small, 2001). Building on the concept's sensitivity to the effort that goes into remembering and commemorating, 
we suggest that the concept of memory work could be developed, on the one hand, to cover memory-related practices at large and, on the other, to recognize the extent to which such work is done in, with and through networks of media. In brief, as practices we understand space-and-time bound, sequenced and socially intelligible activities that are structured and, in turn, structuring the socio-material arrangements in which they have their place and which they, following this logic of practice, constitute and instantiate as the 'site of the social' (Schatzki, 2002).

\section{Mediated memory work}

Most if not all the things we do are conditioned by memory in the broadest sense possible and they involve the past in many different ways. Beyond such a generic relation to memory, the concept of mediated memory work refers to purposeful, memory-related practices that enact instantiations of personal or collective memories through a wide range of historically divergent and culturally heterogeneous practices, such as documenting, registering, capturing, saving, storing, anchoring, commemorating, reminiscing, recalling, evoking, celebrating, framing and eliminating senses and experiences of the past. Mostly, this involves purposive practices in and through which the past is expressively and consciously represented, interpreted, reflected and discursively negotiated. As mediated memory work, these practices, following a distinction made by Couldry (2012: 35 ), may be directly oriented to media, involve media indirectly, or be somehow conditioned by the existence of media.

Seeing social reality as a manifold of practices interwoven with particular arrangements of agents, materialities and cultures directs us to what Hoskins (2011: 23) has named a 'new memory ecology', highlighting that remembering is neither reducible to any one part of these distinct elements nor to an overarching account unifying the diversity of the components. Such an ecological approach instead proposes that remembering 'is made through an ongoing interaction between all the parts' (Hoskins, 2011: 24). Moreover, taking practices as the prime mode of arranging memories as well as a starting point for explaining how they come into being and are made to function, requires us to focus on the recursive performativity of practice arrangements. Mediated memory work thus encompasses practices that are brought into being to perform and constitute senses of the past that intentionally use past emotions, experiences and remnants in arrangements of localities, bodies, social relations, cultures and media technologies. While some of these practices are highly specific to given social arenas, such as documenting bioscientific data (see Bowker, 2008), they usually build on routines and habits dispersed among different sectors of social life.

First, mediated memory work is space-bound, in the sense that its situated enactment happens in localities, that memories are often strongly linked to places, landscapes and monuments, and that practices of remembering themselves construe places (Nelson and Olin, 2003; Nora, 1996; Young, 1993). Second, the somatic dimension of mediated memory work not only acknowledges that such practices invoke mental schemes and scripts and thus relate to the workings of the mind and brain but also reflects the cardinal role that the corporeal and dispositional embodiment of memories plays in mnemonic techniques and in recalling motor sequences, tastes and emotions. This is one of the key themes of 
Bourdieu's $(1977,1998)$ writings on habitus, incorporated competences and social echelons, and they are, for instance, central to the affective remembering and witnessing of traumatic events like the 2005 London bombings (Allen and Brown, 2011; Reading, 2011). Mediated memory work is, third, connected to the ways people build up and retain a sense of individuality and personhood, and it also relates them to different relevant collectives by, for instance, imagining others as part of a commemorative community, by sharing personal memories or by constructing the idea of continuity (or difference) between the self and others (Connerton, 1989). Connected to that, mediated memory work is, fourth, dialectically embedded in culture, that is, it evolves in and instantiates more or less collectively shared and normative meanings, sets of knowledge, habits, conventions and mores which institutionalize, ritualize and dispose what is remembered and how it is remembered (see Assmann, 2011). In other words, cultures furnish the form and substance of remembering as well as the intelligible, feasible and appropriate practices of remembering, and, at the same time, cultures are construed in terms of such culturally integrative types of mediated memory work (van Dijck, 2007: 7).

Fifth, mediated memory work has a material basis (Bowker, 2008; Van House and Churchill, 2008) and relies on technologies artificially inscribing and archiving the past, as noted in such fields as media archaeology (Ernst, 2013; Parikka, 2012). Media technologies, be they mechanical, electronic or digitally networked - such as films, social networking sites, photo albums, diaries and so on - afford means for people to work on and with memories. As such, Couldry (2012: 13) stresses, it is necessary to consider media as 'intersections between technological, economic, social and political forces' and, ultimately, as a 'vast domain of practice' (Couldry, 2012: 44). ${ }^{2}$ Hence, to account for the enabling and constraining features of media, van Dijck (2007: 2) conceives of a 'mutual shaping of memory and media'. In mediated memory work, the different media do not just assist us to materialize and make accessible past events and experiences. They are also pivotal in constituting the past sui generis as they define and shape how memory work can be done and render such remembering accountable and acceptable.

\section{Challenges of empirically researching mediated memory work}

There are numerous challenges in empirically researching memory practices on the ground (Keightley and Pickering, 2013). For one, performing memories often happens in the privacy of people's homes and between other activities. Memories may be liminal and ephemeral, although this does not make the practices themselves or the outcomes of such practices any less culturally significant or meaningful to those construing memories and memorabilia. Practices of mediated memory work are embedded in daily life and quotidian dispersed routines which are difficult to observe because they happen in intimate settings, are interrelated with other (memory) practices or happen on the go, such as the swift uploading of a personal photo to Instagram via a mobile device. Often, people might not even be aware of the particular mnemonic dimension of objects omnipresent in their mundane activities. Consider, for example, the photos of loved ones many carry in their purses or wallets; occasionally, these pictures are consciously noticed and even shared with others, while at other times they might not receive any attention at all. 
More fundamentally, the empirical reconstruction of mediated memory work has to acknowledge that any attempt to explicitly explain the largely tacit logic of practice is destined to fail due to practice's ineffable qualities, which largely exceed social science methods' ability to know them (Bourdieu, 1998). In consequence, what is needed is a reflexive 'method assemblage' (Law, 2004: 42) with regard to the fields, actions and circumstances studied. Ultimately, any endeavour to examine the multi-faceted arrangements of mediated memory work has to manage the complexities of their interrelations.

Thus, in order to account, first, for the different layers of memory practices and the embeddedness of memory objects in everyday life and culture, and, second, to address the challenge of finding viable ways to reflect the practical accomplishment of mediated memory work, we argue for a mixed method approach. We next consider individual cases taken from the Cuban-American community in Miami, Florida. Data was gathered through interviews, participant observation, focus groups and numerous ethnographic encounters in the field. We do not aim to be exhaustive but seek to develop the notion of mediated memory work through three instances drawn from a particular piece of fieldwork. These are a septuagenarian Cuban exile making a donation to an archive; a woman in her mid-twenties of Cuban descent expressing her feelings and thoughts through blogging; and, finally, the mediated reiteration of personal narratives and life histories feeding into the collective memory of the Cuban-American community. The first example tells of the significance of objects in memory practices. The second case stresses (mediated) relations and the communal quality and emotional charge of memory work. The third example highlights the way personal narratives feed into mediated discourses and become dominant narratives of a collective past and a shared identity. Before presenting these cases in detail, we provide a brief overview of the history of migration from Cuba to the United States.

\section{Cuban migration to the United States}

There has long been an exchange of people and goods between Cuba and the United States. Migration from Cuba to the United States intensified significantly after the socalled Cuban revolution in 1959, when the rule of Fulgencio Batista ended and Fidel Castro took over Havana. Miami and south Florida developed into the capital of the Cuban exile community. Originally a rather homogeneous group, the exile community has diversified over the past 50 years through roughly three sequential events: the first exiles to arrive in the 1960s and 1970s were members of Cuba's middle and upper class. The majority were white professionals and their families (García, 1996: 13-15). Even though they had to leave their possessions behind, the early exiles, also often referred to collectively as the historic exile (el exilio histórico), managed to get back on their feet quickly, thanks to their good education and their entrepreneurial spirit. For years many exiles held on to the belief of a swift return to the island (Pérez Firmat, 1995), but with the failed Bay of Pigs invasion in April 1961 and with the passage of time, it became apparent to most that the moment of return might never arrive. The year 1980 brought the so-called Mariel Boatlift, during which a pressured Fidel Castro allowed US boats to dock in the harbour of Mariel to pick up those Cubans who wanted to leave the island. This migration wave of approximately 125,000 people, arriving between early April 
and October, significantly changed the composition of the exiles (Portes and Stepick, 1993). Their arrival coincided with that of another group of migrants arriving from Haiti, which led to serious challenges for institutions and the maintenance of social cohesion (Sándoval, 1986). In addition the migrants who arrived then had already experienced 20 years under Castro's rule. Their memories therefore potentially challenged those of previous arrivals. The 1990s again were characterized by the rafter (balsero) crisis. Cubans tried to cross the Florida Straits in makeshift floating devices. The balseros can be characterized as economic migrants lacking - at least initially - the political engagement that el exilio histórico seemed to thrive on. In the meantime, second-, third- and fourth-generation Cuban-Americans grew up in south Florida as American citizens. Some have acquired a very strong sense of their roots and the exile mentality that has been an identity trait of their parents and grandparents. From these circumstances of migration alone, Cuban-Americans in Miami thus form a diverse group of people with varied interest in, and opinions on, issues around Cuban politics and USCuban relations.

This is the cultural and historical backdrop against which the described mediated memory practices take place. Diasporic groups allow us to investigate the cultural, material and spatio-temporal relations of their memory-inclined practices. This holds especially true, when research is conducted from an etic perspective; with the researcher having a different cultural background from those observed, little is considered 'normal' and 'known'.

\section{Doing mediated memory work: archives, blogs and stories}

Archives have been considered a classic locus of situating and storing memory objects (Ernst, 2013). While archives are often in the hands of institutions, such as universities or museums, archival work partly thrives through individuals contributing documents and objects from their belongings, which enhances the public collection with personal accounts and compilations of the remains of a disappearing culture. This is particularly true for the Cuban Heritage Collection at the University of Miami. The collection is home to a large number of artefacts, including books, postcards, periodicals, official and personal manuscripts, maps and photographs as well as digital material. Everything in the collection is either directly from Cuba, deals in some way with life on the island or has meaning for and is related to members of the global Cuban diaspora. The material includes items from the colonial past to the present. The significance of the Cuban Heritage Collection is underlined by the continuous support it has received from members of the Cuban community based in Miami and elsewhere.

The Cuban man whose mediated memory work and, in particular, memory objects we focus on here, is in his seventies and lives in Puerto Rico. He visits the archive two to three times a year, while simultaneously paying a visit to his extended family in Miami. The informant was born in Cuba and then left as a young adult after Fidel Castro had overthrown the Batista government. In 2008, he brought several postcards and books as a donation to the Cuban Heritage Collection. The action of personally delivering the objects to the collection is of course preceded by having bought, found or inherited them in the first place, as well as by handling, storing and, at times, displaying them 
as precious objects in his home for a period of time. At some point, the decision was made to donate them to the collection as a contribution to the wider community so that others could make use of them in some way. Moreover, prior to his visit to the archive, donating the pieces involved contacting the staff of the Cuban Heritage Collection to evaluate their interest in the material and finally travelling to Florida to personally see them added to the resources of the collection. As one of the staff of the Cuban Heritage Collection commented, this was a very common occurrence; rarely a week goes by without Cubans or people of Cuban descent visiting the collection to donate material that has been in the hands of their family. She saw this as a way for people to 'do something for Cuba'.

The objects they donate are, for the most part, formerly widely distributed media materials characteristic of a period of Cuban culture during which the archive's benefactors themselves have lived and that they cherish as temporally and spatially inaccessible. First, in personally appropriating these vestiges and, second, in bestowing them on a prestigious institution for communal use and appreciation, this group of people assembles, conserves and then transforms documents of a bygone era that shift from forming part of a dispersed and private, though distinctive Cuban-American reminiscing, to become added to resources for institutionalized public memory. These objects are strongly linked to Cuba as they mostly stem from the island's output of printed Spanishlanguage publications, that then existed during, as it were, an interregnum in Puerto Rico (or other exile homes), before moving to an archive situated in Miami as its definite (or, when there is still hope for a return or some form of future exchange between Cuba and other locales of the Cuban-American exile, penultimate) place of custody. It is to a large extent their origin in Cuban culture and daily life that gives them meaning for their owners, but it is also the itinerary these objects have taken - from Cuba to Puerto Rico to south Florida - and the place they are in now, an archive, that make them multi-layered memory objects and allows others to use them.

We can observe the interplay between single collectors, the immediate community and the wider collective. In this example, it is the individual who instigates the contribution of memory objects to a collection, contrary to the more common case in which institutional memory agents accumulate and curate things people do not necessarily find memorable. As artefacts of Cuban memory, these archived materials are initially meaningful to the donor and the commemorative circles he and his possessions become involved in, but there is a sense that such books and postcards, which once circulated widely among Cubans, might be useful for the Cuban-American community as well as for the wider public and researchers. Through the placement of these objects in the collection, they can potentially carry greater significance, and their meaning is further developed by being set and sheltered in relation to similar objects in the same collection.

Overall, acts of donating material and mostly media remnants from numerous private holdings to a small number of communal public resources are not limited to the CubanAmerican community. Yet they are peculiar and common to Cuban-American memory work as this practice brings together, preserves, makes visible and accessible the patchy record of Cuban popular culture so as to bridge, at best, inter-communal boundaries and different levels of acquaintance with and obligation to Cuban heritage. Donating is a 
widespread and ostentatious practice met with qualifications regarding the extent and the significance of the gifts; it is grounded by social imaginaries that value the act of donating not just as preserving and doing good but as a required and almost obligatory deed in the face of a dissolving material culture and a transforming community. The vernacular practice follows notable examples of generously giving and, as a civic benefit, it is appreciated by members of the community and beyond. Most of the collected items are published materials which are valued both as containers of texts, images and other sorts of Cuban representations and as evidence of Cuba in their own right.

The second example, which is illustrative of memory practices and their interplay with face-to-face and mediated relationships, is that of a young Cuban-American whose grandparents formed part of the first wave of exiles and who came to Miami in the early 1960s. Her parents thus had left Cuba as young children - and even though they do not have personal memories of Cuba, the nostalgia for the 'stolen life' on the island meanders through the generations and even forms a significant part of what it means for all three generations to be Cuban-American in Miami. The inter-generational sentiments of loss and the unattainable place are kept alive through personal conversations, keepsakes and recurring narratives found in Cuban-American radio shows, for example. To them, the emotional bonds growing from such sentimental contemplations are exacerbated even on a somatic level by the climatic and scenic similarities between south Florida and parts of Cuba, as Miami 'feels like' home. The same holds true for analogous architectural features and culinary experiences on both sides of the Florida Straits. One CubanAmerican female informant in her early twenties summarized these experiences as follows:

In Miami you are surrounded by this, the constant talk, what's going on? Why is it happening? And so you develop this sense of obligation ... this really deep nostalgia for a country you have never been to. You feel like ... I feel as if I was born there, almost, to a certain degree. As much as I do feel American [I also feel] this sense of nostalgia that I share with my parents. And I think it goes back to the roots, and the close links to the culture over there that we develop here. And through that you have the drive and you have the necessity to follow what they [her parents and grandparents] did. (Interview with Lohmeier, Miami, 27 October 2008)

On the one hand, this informant's statement shows the rich configuration of the realm of colloquial memory she draws from with attachment to a place lost, acknowledgement of a Cuban-American culture as well as continuing ties to, and responsibilities for, two homelands. What, on the other hand, also becomes obvious from this quote is her proficiency in talking about these matters in terms of nostalgia and emotional adherence, and how these feelings are passed down through the generations.

For another informant encountered in the field, a way of channelling such talking about personal sentimental feelings and belonging is through the mediated memory work of writing a blog that deals with issues of exile memory and Cuban-American life. In contrast to many others of her age, this Cuban-American blogger has been to Cuba herself. Thus, in addition to the family tales and conversations, as well as the plethora of mediated narratives of pre-revolutionary $\mathrm{Cuba}$, she could draw on personal and current experiences of the island. As she recounts, going to Cuba - something that is still controversial among the Cuban-American community in Miami - was highly enlightening for 
her and led her to question the limits in which engagement with and for Cuba has been allowed to take form, and the ways mediated memory in Miami is articulated. What makes the situation more complex is that she chose not to tell her grandparents about her visit to Cuba as she feared this would cause too much upheaval in her family. Travelling to Cuba was a rich experience that changed her perspective on the dominant narratives of how Cuba should be remembered and how the Cuban government should be related to. ${ }^{3}$

My grandparents always talked about how things were in Havana, their experiences and needing to leave and just ... you know, the struggle that they had to go through. And what people living in Cuba currently have to deal with and ... so it's always been a matter that is near and dear to my heart. (Interview with Lohmeier, Miami, 24 October 2008)

The metaphors she employs to express the significance as well as the emotional depth evoked by the memories of her grandparents and how they talk about their memories suggest the corporeal and the discursive dimensions that make up Cuban-American mediated memory work.

It is within this gamut of lived and compassionate experiences that she blogs about Cuban and Cuban-American issues. Even though this might at first seem like an intellectual and solitary exercise, her writing process is essentially informed by witnessed, personally felt and thus testified experiences of life in Miami and Cuba as well as by kinship accounts and migrant media discourses on Cuban-American things past and present. The communal aspect of blogging is also underlined through the technical affordances of the media environment in which she operates as she blogs to a personal audience mostly comprising friends and acquaintances who talk back to her and comment on her musings. In order to spread new posts she announces them on her Facebook profile and thereby shares her impressions with relevant circles. She thus adds her views and expressed feelings to the record of communal texts and contributes to a shared sentimental discourse herself.

The third example is that of narrating and remediating life stories feeding into the collective memory of the Cuban-American community. An exemplary account of a biographical narrative comprising moments of Cuban youth, mid-life migration and exile, characteristic of a class and the first generation of Cuban-Americans, can be found on a plaque at the Roberto C. Goizueta Pavilion, home to the Cuban Heritage Collection at the University of Miami. The plaque reads:

Roberto C. Goizueta

November 18, 1931 - October 18, 1997

Roberto C. Goizueta was born in Cuba in 1931. He attended Colegio de Belén and later Cheshire Academy where he learned English. Majoring in chemical engineering he graduated from Yale University in 1953. The following year on July $4^{\text {th }}$, The Coca-Cola Company in Cuba hired him as a chemist. In 1960, after the Communists assumed power in Cuba and nationalized businesses, he made a fateful decision. Roberto, his wife Olguita and their children left Cuba for Miami. This experience changed his life and his outlook forever.

A Cuban emigrant seeking freedom, Roberto C. Goizueta personified the classic American dream. Within 30 years of leaving Cuba, he was leading an American company that symbolized 
freedom around the world - The Coca-Cola Company. Throughout his career the creation of value for the company's share owners was his passion. During his 16 years as chairman and chief executive officer, the Company's value increased from $\$ 4$ billion to $\$ 145$ billion. Upon his death, Fortune Magazine named The Coca-Cola Company 'America's Most Admired Corporation' for a second consecutive year.

Roberto C. Goizueta was more than a business leader. He was the ideal citizen who believed that every person who enjoys freedom and opportunity has a duty to cherish, protect and nurture it. He strived to make America stronger, not only through his inspirational and exceptional business leadership, but also through his generous educational and philanthropic contributions.

This community, this nation and our world have been deeply influenced by the life, mission and presence of Roberto C. Goizueta.

Even though this story tells a model migrant career and is filled with superlatives, it is by no means exceptional in its basic structure. A few years after their arrival, many of the early exiles were living some kind of American dream thanks to their excellent education, their entrepreneurial spirit and strong communal support. Of course Miami's aptness as a space for economic growth and potential social dynamics for certain groups played a part in this as well.

In terms of collectively remembering the early phase of exile, stories like that of Roberto C. Goizueta form a key part in the development of an exile mentality, which is still prevalent among great parts of the Cuban-American community today. Characteristics attributed to Cuban-Americans in such stories, have been adopted by their children and grandchildren, as this quote from a Cuban-American informant in his early twenties underlines:

One could argue that the reason why we have Cubans in the House [of Representatives] and Cubans in the Senate and lots of prosper in Miami is because of the fact that we have laws that somehow favour our prosperity and in that sense allow us to achieve these things. Then again, we are all hard-working, not to discredit the hard work of the many individuals in this community. (Interview with Lohmeier, Miami, 9 June 2006)

Young Cuban-Americans repeatedly point towards the characteristics of their grandparents, and the stories surrounding their grandparents' and parents' success in Miami. These are retold and broadcast among the Cuban-American sub-communities via different types of media and forms of communication. Far from being private family stories only, the retold accounts of abandoning a life and finding a new one are disseminated through autobiographical books, periodicals, Spanish- and English-language newspapers, and especially Cuban-American radio (Lohmeier, 2014).

\section{Conclusion}

Our analysis of Cuban-American memory-making has shown how communally intelligible activities are performed to construe, appropriate and diffuse the issues, stories and materials relevant to the heterogeneous groupings and generations of a migrant 
community. At least equally important for the circulation of commemorative themes and objects constitutive of Cuban-American remembrance is the social integration and reproduction that comes with the enactment of common types of Cuban-American mediated memory work. Through participating in those practices, people become and remain members of the community as they actively and to some extent publicly commit themselves to an understanding of past events, experience attachment to places, people, objects and actions defined as Cuban-American, as they express feelings in terms of nostalgia and inter-generational obligations, and as they employ emblematic biographies to narrate, contextualize and remember their and others' life stories.

The members of the Cuban-American community make use of a host of artefacts, discursive strategies and forms of mediated communication to form, uphold and transform communal bonds and boundaries. We have considered the mediated memory work of Cuban-Americans and explored the ways in which they handle and devise mnemonic relations, places and things. Therefore, beyond recording of the stock of memorables deemed typical of a collective, zooming in on the practices of doing memory, we have argued, draws attention to the necessity for theorizing and analysing their 'ecological' relations. Consequently, besides being, in the first instance, a contribution to the vocabulary and conceptual grounding of the mediation of memories, this investigation of mediated memory work also connects with the debates on memory studies' methodological and methodical propositions.

\section{Funding and acknowledgements}

This article grew from discussions started in the Digital Memories Seminar organized by Andrea Hajek at the Centre for Media and Culture Research, London South Bank University, July 2012. We offer our thanks to the participants for their comments on earlier versions of this article. Financial support from the German National Academic Foundation as a personal dissertation grant to Christian Pentzold and the Carnegie Trust for the Universities of Scotland for fieldwork in Miami, FL to Christine Lohmeier is gratefully acknowledged.

\section{Notes}

1. We draw on several research projects. In an ethnography of Wikipedia authors, Pentzold studied the platform and the project as a global memory place. He was also involved in a project reconstructing the transmedia discourse on John Demjanjuk, a former guard at a Nazi extermination camp convicted for war crimes (see Pentzold, 2009; Pentzold and Sommer, 2011). The empirical case study derives from Lohmeier's PhD thesis on Cuban-Americans and the Miami media (Lohmeier, forthcoming).

2. For praxeological perspectives on media in general, see Bräuchler and Postill (2010).

3. For decades, the discourse perpetuated in Cuban-American media, radio in particular, has been dominated by hardline views. Hardliners are Cuban-Americans who strongly oppose any negotiation with the Cuban government and are in favour of the trade embargo.

\section{References}

Allen M and Brown SD (2011) Embodiment and living memorials: the affective labour of remembering the 2005 London bombings. Memory Studies 4(3): 312-327.

Assmann J (2011) Cultural Memory and Early Civilization. Cambridge: Cambridge University Press. 
Bergson H (1988 [1896]) Matter and Memory. New York: Zone Books.

Bourdieu P (1977) Outline of a Theory of Practice. Cambridge: Cambridge University Press.

Bourdieu P (1998) Practical Reason. Stanford, CA: Stanford University Press.

Bowker G (2008) Memory Practices in the Sciences. Cambridge, MA: MIT Press.

Bräuchler B and Postill J (eds) (2010) Theorising Media and Practice. Oxford: Berghahn.

Connerton P (1989) How Societies Remember. Cambridge: Cambridge University Press.

Couldry N (2012) Media, Society, World. Cambridge: Polity.

Edy J (2006) Troubled Pasts: News and the Collective Memory of Social Unrest. Philadelphia, PA:

Temple University Press.

Erll A and Rigney A (eds) (2009) Mediation, Remediation, and the Dynamics of Cultural Memory. Berlin: de Gruyter.

Ernst W (2013) Digital Memory and the Archive. Minneapolis: University of Minnesota Press.

Foot KA, Warnick B and Schneider SM (2005) Web-based memorializing after September 11. Journal of Computer-Mediated Communication 11(1). Available at: http://jcmc.indiana.edu/ vol11/issue1/foot.html (accessed 7 May 2013).

García CM (1996) Havana USA: Cuban Exiles and Cuban Americans in South Florida, 19591994. Berkeley: University of California Press.

Garde-Hansen J (2011) Media and Memory. Edinburgh: Edinburgh University Press.

Garde-Hansen J, Reading A and Hoskins A (eds) (2009) Save as ... Digital Memories. Basingstoke: Palgrave Macmillan.

Haskins E (2007) Between archive and participation: public memory in a digital age. Rhetoric Society Quarterly 37(4): 401-422.

Haug F (1992) Beyond Female Masochism: Memory-work and Politics. London: Verso.

Hess A (2007) In digital remembrance: vernacular memory and the rhetorical construction of web memorials. Media, Culture \& Society 29(5): 812-830.

Hoskins A (2009) The mediatisation of memory. In: Garde-Hansen J, Reading A and Hoskins A (eds) Save as ... Digital Memories. Basingstoke: Palgrave Macmillan, pp. 27-43.

Hoskins A (2011) Media, memory, metaphor: remembering and the connective turn. Parallax 17(4): 19-31.

Keightley E and Pickering M (eds) (2013) Research Methods for Memory Studies. Edinburgh: Edinburgh University Press.

Kuhn A (2010) Memory texts and memory work: performances of memory in and with visual media. Memory Studies 3(4): 298-313.

Law J (2004) After Method. London: Routledge.

Livingstone S (2009) On the mediation of everything. Journal of Communication 59(1): 1-18.

Lohmeier C (2014) Cuban Americans and the Miami Media. Jefferson, NC: McFarland.

Mayer-Schönberger V (2009) Delete: The Virtue of Forgetting in the Digital Age. Princeton, NJ: Princeton University Press.

Neiger M, Zandberg E and Meyers O (eds) (2011) On Media Memory. Basingstoke: Palgrave Macmillan.

Nelson RS and Olin M (eds) (2003) Monuments and Memory, Made and Unmade. Chicago: University of Chicago Press.

Nora P (1996) Realms of Memory. New York: Columbia University Press

Olick JK, Vinitzky-Seroussi V and Levy D (eds) (2011) The Collective Memory Reader. Oxford: Oxford University Press.

Onyx J and Small J (2001) Memory-work: the method. Qualitative Inquiry 7(6): 773-786.

Parikka J (2012) What is Media Archaeology? Cambridge: Polity.

Pentzold C (2009) The online encyclopaedia Wikipedia as a global memory place. Memory Studies 2(2): $255-272$. 
Pentzold C and Sommer V (2011) Digital networked media and social memory. Aurora. Revista de Arte, Mídia e Política 10: 72-85.

Pérez Firmat G (1995) Next Year in Cuba: A Cubano's Coming-of-Age in America. Houston, TX: Arte Público Press.

Pickering A (1995) The Mangle of Practice: Time, Agency and Science. Chicago: University of Chicago Press.

Portes A and Stepick A (1993) City on the Edge: The Transformation of Miami. Berkeley: University of California Press.

Reading A (2003) Digital interactivity in public memory institutions: the uses of new technologies in Holocaust museums. Media, Culture \& Society 25(1): 67-85.

Reading A (2011) The London bombings: mobile witnessing, mortal bodies and globital time. Memory Studies 4(3): 298-311.

Rossington M and Whitehead A (eds) (2007) Theories of Memory: A Reader. Edinburgh: Edinburgh University Press.

Sándoval MC (1986). Mariel and Cuban National Identity. Miami: Edition SIBI.

Schatzki T (2002) The Site of the Social. University Park: State University of Pennsylvania Press. van Dijck J (2007) Mediated Memories in the Digital Age. Stanford, CA: Stanford University Press.

van House N and Churchill E (2008) Technologies of memory. Memory Studies 1(3): 295-310.

Young JE (1993) The Texture of Memory. New Haven, CT: Yale University Press.

Zandberg E (2010) The right to tell the (right) story: journalism, authority and memory. Media, Culture \& Society 32(1): 5-24.

Zelizer B (2000) Remembering to Forget: Holocaust Memory Through the Camera's Eye. Chicago: University of Chicago Press. 